American Journal of Pharmaceutical Education 2019; 83 (4) Article 7221.

\title{
THEME ISSUE
}

\section{An Introduction to Cultural Sensitivity and Global Pharmacy Engagement}

\author{
Naser Z. Alsharif, PharmD, PhD, ${ }^{\mathrm{a}, \mathrm{b}}$ Lisa Brennan, PharmD, ${ }^{\mathrm{c}}$ Jeanine P. Abrons, PharmD, ${ }^{\mathrm{d}}$ \\ Elias B. Chahine, PharmD ${ }^{\mathrm{e}}$ \\ ${ }^{a}$ School of Pharmacy and Health Professions, Creighton University, Omaha, Nebraska \\ ${ }^{\mathrm{b}}$ Editorial Board Member, American Journal of Pharmaceutical Education, Arlington, Virginia \\ ${ }^{c}$ School of Pharmacy, Wingate University, Wingate, North Carolina \\ ${ }^{\mathrm{d}}$ College of Pharmacy, University of Iowa, Iowa City, Iowa \\ ${ }^{\mathrm{e}}$ Lloyd L. Gregory School of Pharmacy, Palm Beach Atlantic University, West Palm Beach, Florida \\ Submitted June 23, 2018; accepted October 11, 2018; published May 2019.
}

\begin{abstract}
Global engagement between schools and colleges of pharmacy in the United States and many regions of the world is increasing. For an enriching and fruitful interaction, sensitivity toward the cultural, ethical, educational, religious, historical, political, regulatory, and practice issues is critical. Lack of sensitivity may negatively impact engagement among students, professionals and other people from different regions of the world. In this special issue, eight papers will introduce general information about five regions of the world that have established and increased global engagements with institutions in the United States: Africa, the Arab world, Asia, the Caribbean, and Latin America. In addition, the special issue will include a paper with key information related to global engagement within the United States. For each paper, the specifics provided about the selected countries include: demographics, culture, climate, pharmacy education, and health care systems, as well as common stereotypes and misconceptions held by and about the people of the country. Further, recommendations for pharmacists and other health care professionals on culturally sensitive engagement will be emphasized. Finally, recommendations for culturally sensitive engagement when US schools are hosting students and faculty members from those regions will be summarized.

The papers are based on literature reviews of databases from 2000 to 2018 and internet searches with specific keywords or terms, such as cultural sensitivity, global, pharmacy, stereotypes, and ethics. Additional keywords are identified in individual papers on specific regions. Authors for each paper consist of practitioners with experience in travelling to and hosting students and professionals from the regions; practitioners with local work experience, and professionals from each region. The special issue is intended to serve as a resource for US schools and colleges of pharmacy currently engaged in or considering future outreach opportunities in these regions, and for those seeking opportunities in the United States. The special issue will provide key information to facilitate culturally sensitive engagement in existing or future relationships.
\end{abstract}

\section{INTRODUCTION}

Global engagement between schools and colleges of pharmacy in the United States and those in other regions of the world, especially in Africa, Asia, the Arab World, the Caribbean, and Latin America, is increasing. Such engagements involve educational, practice, scholarly, service, and cultural experiences. ${ }^{1-13}$ With more than $60 \%$ of the world's top 100 universities located in the United States, many international students and faculty

Corresponding Author: Naser Z. Alsharif, School of Pharmacy and Health Professions, Creighton University, 2500 California Plaza, Omaha, NE 68178. Tel: 402-280-1857. E-mail: naseralsharif@creighton.edu members seek higher education and other training and professional opportunities in the United States first. ${ }^{14,15}$ Also, many of these US universities have established global strategic plans and enhanced international recruitment efforts to sustain operations in an increasingly competitive environment. In addition, global citizenship is increasingly being emphasized as part of the pharmacy curriculum, with many students and faculty members seeking opportunities to experience health care systems, pharmacy education, and pharmacy practice in different regions of the world. . $^{1,3,8}$

The regions emphasized in this paper have experienced many changes to pharmacy education and practice in recent years. In several countries, numerous schools 


\section{American Journal of Pharmaceutical Education 2019; 83 (4) Article 7221.}

and colleges of pharmacy have been established with emphasis on clinical pharmacy education and quality experiential training. The growth of pharmacy services throughout the respective regions, albeit with variable resources, has furthered interest in postgraduate education and training, knowledge and skills in clinical pharmacy services, new job opportunities for pharmacists, and other innovative pharmacy services. This also has provided a diversity of advanced pharmacy practice experiences (APPEs) for international students and professional practice opportunities for international residents to participate in throughout the world. Further, the World Health Organization (WHO) and the International Pharmaceutical Federation (FIP) have actively highlighted the role pharmacists can play in the health care system as a caregiver over the past several years. These organizations published a handbook in 2006 titled Developing Pharmacy Practice: A Focus on Patient Care. ${ }^{16}$ More recently, the WHO published a report addressing guidelines for scaling up health professionals' education and health care training, ${ }^{17}$ while the FIP Pharmacy Education Taskforce published a pharmacy education action plan in $2008^{18}$ and a set of core behavioral competencies for basic pharmacy practitioners in 2012. ${ }^{19,20}$ In addition, the WHO, FIP and United Nations Educational Scientific and Cultural Organization (UNESCO) outlined a strategy to meet present and future societal and pharmaceutical health needs around the world. $^{21}$

Providing education and training programs across borders for educators, practitioners, and pharmacy students can serve as one mechanism for addressing the global need for health care workers, especially if those overseas travelers are equipped with strategies for initiating educational, service, and practice change within their home country when they return. The WHO estimates that the number of new jobs for health workers (including pharmacists) needed by 2030 is 40 million, leaving a potential shortfall of 18 million health care workers. ${ }^{22}$ All countries of the world, including the United States, have a role to play in educating and training individuals to meet global workforce needs. This emphasizes the importance of institutions and individuals being culturally sensitive in their approach to engaging with colleagues from around the world. ${ }^{23}$ Thus, many schools and colleges of pharmacy and governmental agencies around the world are emphasizing strategic plans to improve on pharmacy education and practice.

Recently, the curriculum in many schools and colleges of pharmacy and residency programs around the world has shifted to meet international standards, especially those set by the Accreditation Council for Pharmacy Education (ACPE) and by the American Society of
Health-System Pharmacists (ASHP). ${ }^{24,25}$ Additionally, a trend of international institutions seeking ACPE and ASHP certification or accreditation has been seen. This has resulted in many international schools and colleges of pharmacy and health systems reaching out to US pharmacy organizations and institutions for mentorship and to partner with them to improve the quality of didactic instruction and experiential education in their institutions. This guidance includes postgraduate education and training to meet quality requirements at all levels. Table 1 lists international schools and colleges of pharmacy with ACPE accreditation or certification status. ${ }^{24,25}$ Certification by the ACPE is granted or continued to a professional pharmacy program in a country outside the United States that "demonstrates compliance with most or all quality criteria and meets all ACPE's requirements for such recognition." ${ }^{24}$ Table 2 lists international postgraduate residency programs with ASHP accreditation status. ${ }^{26}$

Further, many international institutions are now encouraging US specialty certification examinations as administered by the Board of Pharmacy Specialties (BPS) as a way of demonstrating the quality of training they provide. ${ }^{27}$ The Board reports that as of January 2018, there were 4,038 BPS board-certified pharmacists in 41 countries outside of the United States, a 59.4\% increase over the number in 2016 and accounting for $11.1 \%$ of all boardcertified pharmacists in the world. Egypt is the country with the highest concentration of BPS-certified pharmacists outside the United States. ${ }^{28}$

Historically, misunderstandings between different areas of the world have led to inaccurate perceptions of people and their cultures. One example is the West's traditional orientalist view of people from the East, including those from countries in Africa, the Arab World, and Asia. This orientalist view purports exotic, negative images and stereotypes about people from these countries and has established a psyche of superiority of the Westerners in the minds of the natives of those regions. ${ }^{29}$ These historic misunderstandings continue to exist to some extent. This history affects how people from that part of the world and Westerners interact on both a personal and professional level.

Although Western culture has spread throughout the world, many people outside the United States may have specific stereotypes of America and Americans based on media images or politics. Individuals outside the United States also may not be familiar with the diversity of the American people within a region of the United States or across the different regions and cities. In addition, while pharmacy education and practice in the United States is considered an ideal model by many institutions and pharmacy practitioners around the world, many may not be 
American Journal of Pharmaceutical Education 2019; 83 (4) Article 7221.

Table 1. International Schools and Colleges of Pharmacy with Accreditation or Certification Status

\begin{tabular}{|c|c|c|c|}
\hline School/College of Pharmacy & Location & $\begin{array}{l}\text { ACPE Accreditation } \\
\text { (Yes or No) }\end{array}$ & $\begin{array}{l}\text { ACPE Certification } \\
\text { (Yes or No) }\end{array}$ \\
\hline $\begin{array}{l}\text { Ajman University College of Pharmacy and } \\
\text { Health Sciences }\end{array}$ & $\begin{array}{l}\text { United Arab } \\
\text { Emirates }\end{array}$ & No & Yes \\
\hline $\begin{array}{l}\text { Al Ain University of Science and } \\
\text { Technology College of Pharmacy }\end{array}$ & $\begin{array}{l}\text { United Arab } \\
\text { Emirates }\end{array}$ & No & Yes \\
\hline $\begin{array}{l}\text { Applied Science Private University Faculty } \\
\text { of Pharmacy }\end{array}$ & Jordan & No & Yes \\
\hline $\begin{array}{l}\text { Jagaduru Sri Shivarathreeswara (JSS) } \\
\text { University College of Pharmacy }\end{array}$ & India & No & Yes \\
\hline $\begin{array}{l}\text { Jordan University of Science and } \\
\text { Technology, Faculty of Pharmacy }\end{array}$ & Jordan & No & Yes \\
\hline $\begin{array}{l}\text { King Faisal University College of Clinical } \\
\text { Pharmacy }\end{array}$ & Saudi Arabia & No & Yes \\
\hline King Saud University College of Pharmacy & Saudi Arabia & No & Yes \\
\hline Lebanese American University & Lebanon & Yes & No \\
\hline Near East University Faculty of Pharmacy & Northern Cyprus & No & Yes \\
\hline Qassim University College of Pharmacy & Saudi Arabia & No & Yes \\
\hline $\begin{array}{l}\text { The University of Jordan School of } \\
\text { Pharmacy }\end{array}$ & Jordan & No & Yes \\
\hline $\begin{array}{l}\text { University of Petra, Faculty of Pharmacy and } \\
\text { Medical Sciences }\end{array}$ & Jordan & No & Yes \\
\hline
\end{tabular}

Abbreviations: ACPE $=$ Accreditation Council for Pharmacy Education ${ }^{25}$

aware that pharmacy education and practice in the United States face some of the same problems and barriers present in other parts of the world.
Based on these challenges, the papers in this special issue address the concept of cultural sensitivity within the context of global engagement, and more specifically, in

Table 2. International Institutions with the ASHP Residency Accreditation Status

\begin{tabular}{lll}
\hline Institution & \multicolumn{1}{c}{ Program } & \multicolumn{1}{c}{ Location } \\
\hline Abu Dhabi Health Services Company & PGY1 Pharmacy & United Arab Emirates \\
American University of Beirut Medical Center & PGY1 Pharmacy & Lebanon \\
Children's Cancer Hospital Egypt & IPPR International Pharmacy Practice & Egypt \\
Cleveland Clinic Abu Dhabi & PGY1 Pharmacy & United Arab Emirates \\
King Abdulaziz Medical City - Central Region & PGY1 Pharmacy & Saudi Arabia \\
King Abdulaziz Medical City - Western Region & PGY1 Pharmacy & Saudi Arabia \\
King Faisal Specialist Hospital and Research Center & PGY1 Pharmacy & Saudi Arabia \\
& PGY2 Cardiology Pharmacy & \\
& PGY2 Oncology Pharmacy & \\
& PGY2 Solid Organ Transplant & \\
King Hussein Cancer Center & Pharmacy & Jordan \\
King Khalid University Hospital and King Saud & PGY1 Pharmacy & Saudi Arabia \\
University Medical Center & PGY2 Pharmacy & \\
Hamad Medical Corporation & & Qatar \\
MMM Holdings, LLC & PGY2 Pharmacy & Puerto Rico \\
Shaukat Khanum Memorial Cancer & PGY1 Managed Care Pharmacy & Pakistan \\
Hospital and Research Center & IPPR International Pharmacy Practice & \\
University of Puerto Rico School of Pharmacy & PGY1 Community-based Pharmacy & Puerto Rico \\
VA Caribbean Healthcare System & PGY1 Pharmacy & Puerto Rico
\end{tabular}

Abbreviations: PGY1=Postgraduate Year One Residency; PGY2=Postgraduate Year Two Residency; ASHP=American Society of HealthSystem Pharmacists ${ }^{26}$ 


\section{American Journal of Pharmaceutical Education 2019; 83 (4) Article 7221.}

pharmacy. In doing so, it was also important to provide a brief description of the history, health care system, and status of pharmacy education and practice in the respective regions of the world. Examples from other countries with institutions that have established collaborative efforts with US entities will be emphasized. To set the stage for the aforementioned papers, in this introduction, key terms are defined and discussed, general methods used are explained, and the organization of the papers is described.

\section{Culture}

Culture has been defined in many different ways, but in general it is identified as "a dynamic system of rules, explicit and implicit, established by groups in order to ensure their survival, involving attitudes, values, beliefs, norms, and behaviors, shared by a group but harbored differently by each specific unit within the group, communicated across generations, relatively stable but with the potential to change across time." ${ }^{30}$ This definition encompasses key aspects that are critical to successfully engage with any group of people. Even when culture is shared by a group and relatively stable, it is important to recognize that there are variations over time and certainly at the individual level. Thus, it should not be assumed that everyone within a culture will have the same attitudes, beliefs, norms, and behaviors. However, at the same time, knowledge of key aspects of shared culture is important because it affects how people within a culture think and act. Developing respect and understanding of the components of a culture among different groups, as in the case of global engagements, is critical to establishing sustainable relationships.

\section{Cultural Sensitivity}

Cultural awareness or sensitivity is the first step towards cultural competency. It is the recognition of and respect for the different cultures that exist within a society and across the globe. Further, it recognizes that differences between cultures do exist and are based on many factors including religion, race, ethnicity, gender, education, nationality, politics, and geographic origin. ${ }^{31}$ Knowledge of and respect for these differences is key in all interactions and in the development of cultural skills. This foundation will challenge readers to address their own biases towards others. As a result, the sense of superiority over the others and the attitude that "my way is the only way" disappears. Consequently, cultural humility becomes part of interacting with people in an egoless way. It requires acceptance of the limitations of one's knowledge and expertise, acknowledgment that everyone can make mistakes and has flaws, and recognition that much is gained by respecting each other as equals. ${ }^{32,33}$ As a result, people who exhibit cultural awareness towards others will develop a positive attitude toward people who are different, and as a result, enjoy more effective and enriching communication and experiences. In fact, literature has emphasized the importance of cultural sensitivity to enable better communication and team building. ${ }^{34}$ Cultural sensitivity also is identified as one of the core values of an effective health care team. ${ }^{35}$ While cultural sensitivity is important in all encounters within a society, an awareness of the different beliefs, values, and customs of others becomes critical when dealing with cultures across the globe. This also becomes paramount for health care professional students and faculty members engaged in educational activities abroad and in the delivery of care to diverse patient populations.

\section{Global Engagement}

While cultural sensitivity is important at the individual level, general logistical aspects of any global engagement also are important to demonstrate cultural sensitivity. These include a structured program beginning with greeting and welcoming guests at the airport; providing an orientation session; coordinating local transportation and housing; training personnel on how to behave appropriately around guests; addressing health and safety issues and what to do in an emergency; attending to guests' spiritual needs and food preferences; and providing meaningful cultural and social activities. ${ }^{4,5,9}$ These structured activities demonstrate a genuine concern for developing a well-planned and purposeful relationship with the guests, and shows hospitality and an awareness of many of the issues that may concern the guests to ensure they have a positive experience. Logistics related to the educational experience also should be addressed including scheduling, types and scope of experiences, communication, site details, and preceptor training and qualifications. ${ }^{5,8}$ Cultural competency has been discussed in much detail within the context of general global engagement; ${ }^{6-38}$ however, training students in the host country in cultural competency is critical, as well. Also, of equal importance is that consideration of cultural humility and assessment of cultural competency should include an awareness of the limitations to current instruments for measuring cultural competency such as differing definitions of culture. ${ }^{39}$

Another important aspect in fostering cultural sensitivity is to consider the challenges experienced by students and faculty members in global engagement activities. The literature has identified communication, cultural differences, and discrimination as challenges experienced by international students in general and specifically by those studying in the United States. ${ }^{40-43}$ Thus, 


\section{American Journal of Pharmaceutical Education 2019; 83 (4) Article 7221.}

collaborative experiences should address such challenges to ensure a successful social and academic experience during the time the students stay in the host country. Support from peers, instructors, and the university are key to helping the students adjust during their stay. Language can be a major barrier and can result in excluding students from participation, loss of confidence, feelings of inequality, worsening mental health, and knowledge translation barriers. ${ }^{44-46}$ Because English is the dominant language in many of the locations where there are global engagement opportunities, having limited English proficiency is a disadvantage for an international student or educator. Efforts should be made by both the sending institution and host partners to help in this regard. ${ }^{47}$ However, attempts by the visiting party to learn aspects of the local language are also important. Some institutions, for example, offer a Spanish class for students on exchange programs in Spanish-speaking countries. In addition, host students and faculty members need to be cognizant of communication barriers and help support and encourage visiting guests to overcome language barriers, so they will feel comfortable to speak and share their opinions and knowledge. Speaking at a slower pace, providing thorough and clear explanations, and using different tools to communicate, including written and visual materials, may help in this regard. Also, the emphasis in communication should be placed on understanding and relaying of ideas rather than on correct grammar and accent. In addition, having limited language proficiency may also result in a student or faculty member having a tendency to copy other people's work. In the United States, students are told to read published material and summarize it in their own words to include in a paper; however, in some cultures students are taught to respect and not question authorities and not to change an author's words. ${ }^{47,48}$ Thus, international students studying in the United States are often more likely to plagiarize. ${ }^{47,48}$ To prevent this problem, an orientation to plagiarism and education about scientific writing, citation, and referencing should be presented. Providing visiting students with access to a university writing center would also be helpful if they will be required to submit written assignments or reports.

\section{Stereotype, Discrimination}

A stereotype is defined as "a fixed, over-generalized belief about a particular group or class of people." 49 The assumption becomes that the stereotype is true for individuals within that group. Stereotypes can be explicit because the individual is willing to verbalize and acknowledge them, or implicit, existing in the individual unconsciousness. Regardless, the concern is when peo- ple start having or exhibiting negative feelings and emotions based on these stereotypes. This may result in prejudicial misconceptions about the group and can lead to discrimination. The resulting danger occurs when people with prejudicial feelings become unwilling to rethink their attitudes and behaviors. As a result, they can easily justify these prejudicial attitudes and behaviors and do not even consider their consequences. ${ }^{50}$ This may result in disastrous relationships, conflicts, and harm to targeted groups. Thus, addressing stereotypes on a collective or individual level with the people of the host or sending country is key to building fruitful and healthy relationships.

\section{Acculturation}

Cultural differences often play a major part in alienating the visiting guest, and purposeful efforts on the part of the hosts are needed to establish a feeling of social belonging. This is important because acculturation stress, culture shock, lack of self-esteem, lack of social support, and discrimination are factors identified in the literature that may deter from a positive cultural and educational experience. ${ }^{51-53}$ When individuals leave their home to live in another culture, they encounter many obstacles. Traditionally, the term "culture shock" has been applied to this experience. However, psychologists prefer acculturative stress, providing for a broader definition that includes both positive and negative impacts. ${ }^{51}$ The earliest model of culture shock, developed by Oberg ${ }^{52}$ and Lysgaard, ${ }^{53}$ described a U-shaped model of cultural adjustment developing over four phases. Initially, the honeymoon phase occurs where a person is fascinated by the new culture and excitement is the dominant feeling. A crisis or hostile stage occurs next in which the person becomes irritated by the differences between the new culture and their own, often reacting out of proportion to the incident that brings on these feelings. Eventually, as an individual learns more and becomes increasingly comfortable in the new culture, he or she enters the recovery or adjustment phase. The final phase of cultural adjustment is adaptation of the person to the new culture and acceptance of the place as their alternate home. ${ }^{52,53}$ However, evidence to support this model has been contradictory. ${ }^{54}$ Regardless of whether cultural adjustment occurs in these stages, the person can develop an uprooting disorder, leading to physical and psychological symptoms. ${ }^{55}$

As expected, a person's response to a change in culture is highly dependent on their personality, with six traits in particular showing a correlation to cultural adaptation: openness, conscientiousness, extraversion, agreeableness, neuroticism, and honesty-humility. ${ }^{54}$ In addition, the similarity of the home and host cultures also plays a 


\section{American Journal of Pharmaceutical Education 2019; 83 (4) Article 7221.}

role in promoting a smooth transition. Thus, understanding the diverse cultural skills and identities of the participating students and faculty members is important. Measures should be put in place to increase acculturation of the students, minimize acculturative stress, and socialize the students to help them become more integrated into the cultural and educational aspects of their experience. While American culture has spread to many parts of the world, this is not true everywhere. In countries like China, where there are currently increased opportunities for engagement with the United States, more cultural effort might be needed when hosting Chinese students because of the heightened language barriers, different cultural values, unfamiliarity with American culture, and overall diverse worldviews based on the countries' contrasting political systems. ${ }^{56-58}$ This can also be a factor for US students and faculty members travelling overseas and encountering cultures they are not familiar with. In both situations, efforts should be made to adapt to the local culture instead of expecting hosts to adapt to the culture of the visiting students or faculty members.

Differences in the education culture between countries also should be addressed to ensure the guest feels a sense of academic belonging. Learning styles can play a role in this, depending on the culture. In a collectivist culture, the instructor imparts information in a concise and direct manner. Students are expected to only listen during class, and memorization is emphasized. ${ }^{59}$ Thus, a teacher-centered approach dominates. In an individualistic culture, such as the American culture, critical thinking, active learning, and problem solving are stressed. Thus, a student-centered approach is expected. This variation has implications in verbal and written interactions including the important issue of questioning authority or inadvertently committing plagiarism as mentioned above. ${ }^{47,48}$ For example, in the United States, developing critical thinking, encouraging questions by students, engaging in experiential learning, and challenging established knowledge and concepts are emphasized. ${ }^{59}$ Visiting students who were not trained in this approach to education and are accustomed to being passive learners who simply reproduce information may struggle with giving their opinion and criticizing current knowledge and practices. ${ }^{59-61}$ In fact, in some cases, when attempting to question teachers or preceptors, they may be perceived as rude or not being tactful. Therefore, creating a welcoming educational experience when visiting students are oriented to the expectations of the educational process is important. For a student-centered interaction, this should include informal interactions where teachers take time to talk to the student before and after the educational experience or to participate in social activities with them so that the students become more comfortable and free to ask questions, share opinions, demonstrate initiative, and communicate in a culturally sensitive way. ${ }^{56-61}$ Instructor role modeling by stating, for example, "I do not know" when the student asks a question about something they are not familiar with, can demonstrate to the students that it is acceptable that one does not know everything, and that it is alright if a student attempts a question and ends up giving the wrong answer. This will facilitate better engagement with students, giving them a sense of belonging, and can prevent misconceptions on the part of the teacher that the international student lacks motivation to learn or does not know the subject matter. It is also important to consider the learning style predominant in the country of the student or trainee. Resources for assistance in person or electronically from their teachers and preceptors, or help from academic and counseling services, also should be shared. As with any attempt to address cultural differences, it is important not to generalize the discussion above to all students from any culture and instead to look at commonalities to make the experience a more positive one for all. In addition, emphasizing the potential benefits for both cultures from the engagement, including openmindedness, self-awareness, and cultural sensitivity, is critical. Further, in cultures where faculty-centered learning exists, and authority is emphasized, the hosts should orient visiting students to this. Visiting students should be trained to be tactful when communicating with faculty members, preceptors, and health care providers so as not to disturb the established hierarchy in a negative way, and to act professionally when providing opinions or questioning authority. ${ }^{43,60,61}$

Both cultural and academic differences may potentially lead to hosts forming negative stereotypes about the students prior to, during, or after the experience. This may be because they have general stereotypes or bias about a certain group of students, students' ethnic or religious background, or their respective country of origin. ${ }^{50}$ There are strategies to address these issues, and partners on both sides of the engagement should be challenged to address their own biases and stereotypes. ${ }^{62}$ Holding a cultural sensitivity workshop that addresses general aspects and specifics related to the cultures of the visiting students or educators is crucial before the start of any engagement program. Being aware of existing stereotypes based on historical and political constructs is important, especially in engagements between "developed" and "developing" countries or individuals from home and host countries with a history of colonization. As shared above, many negative stereotypes do exist based on these types of historical and political factors, where, for example, one 


\section{American Journal of Pharmaceutical Education 2019; 83 (4) Article 7221.}

group had a history of being demonized and dehumanized by the other group and holds a belief that the other culture is superior. As shared above, this could be a factor when students and faculty members from Western countries engage with countries in Africa and the Arab world. This inferiority complex may make individuals from those regions feel that they do not have much to offer in such a relationship, when in fact they can enrich the relationship in many ways. On the other hand, those from Western countries may, overtly or covertly, abuse such relationships and play on such a belief to gain financial privileges and advantages, pretend to have expertise in areas in which they do not (something they may not be tempted to do in their home country), or feel that there is not much they can gain from the experience. As such, students and faculty members from Western countries should seek opportunities to engage hosts or guests in a positive way and keep an open mind regarding their experiences.

\section{Ethics and Trust}

Intertwined with the concept of cultural sensitivity and the success of global engagement is having a commitment to upholding key ethical principles, including autonomy, trust, veracity, beneficence, nonmaleficence, self-regulation, solidarity, sustainability, and capacity building. Building a trusting relationship based on these principles is essential, especially in global engagements with countries and regions of the world with a history of mistrust of the West because of colonization of their countries and the resulting deplenishment of resources and marginalized populations. ${ }^{63}$ For example, while the principle of a nation having autonomy is very much emphasized in Western countries, because of a history of colonization and exploitation between the sending and host countries, the concept and other principles may be ignored when dealing with professionals or patients from those countries. An awareness of this anachronism is critical because Western guests may be seen as authority figures by local practitioners and patients. As a result, the hosts may not feel free to share their own opinions or preferences. Also, while the principles of autonomy, telling the truth, beneficence, and nonmaleficence, as defined by Beauchamp and Childress, ${ }^{64}$ are critical, other ethical frameworks should be adopted because cultural differences do exist in how these principles are addressed or emphasized. Childress and colleagues proposed a framework for conducting global research in marginalized communities based on five principles: effectiveness, proportionality, necessity, least infringement, and public justification. ${ }^{64}$ Although proposed for a research framework, these principles also apply to engagement in education to ensure that outreach activities are: purposeful; meet the educational and training needs of the partner; do not infringe in a negative way on local, educational, economical, and workforce factors; and meet the long-term health needs of the local communities. Exercising other ethical principles such as self-regulation would ensure that all partners were acting in the best interest of the relationship and meeting the agreed upon goals. This can only be achieved at the individual level through cultural humility, self-education, self-awareness, self-monitoring, self-evaluation, self-reflection, life-long learning, and self-reformation to maintain competence. ${ }^{65-67}$ Likewise, to maintain solidarity, we must all recognize that we are interdependent and have complementary needs based on our individual strengths and weaknesses. Moreover, sustainability and capacity building should be at the heart of all engagements to ensure that the work that is started can continue by providing the education and training needed and creating a workforce that will sustain efforts for both partners, especially partners with limited resources. This too requires advocacy at the level of regulatory bodies and ministries, innovative mechanisms to address limited resources, outreach to the public, and addressing power dynamics and corruption. ${ }^{68-71}$ All of the aforementioned principles and actions are key to building a trusting relationship and exhibiting cultural sensitivity in all interactions.

An overarching must for all the above guidelines, and especially as members of a profession, is the need to remember that we are bound by a code of conduct. In the United States, 2019 is the $25^{\text {th }}$ anniversary of the most recent revision to the Code of Ethics for Pharmacists. ${ }^{72}$ This code addresses many aspects regarding the conduct of a pharmacist and refers to pharmacists' respecting the dignity of all persons. Students and practitioners should keep their country's code of ethics in mind as they participate in global engagement to ensure that they do not conduct themselves in ways contrary to what is expected of them by their own country. In addition, pharmacists should familiarize themselves with any professional, religious, social, and/or political factors in the host country that may impact their ability to maintain their country's code of conduct for pharmacists and those for other health care professionals.

\section{Cultural Competency in Pharmacy Practice}

Cultural competency is important when addressing the healthcare needs of a diverse population. The 2013 Center for the Advancement of Pharmacy Education (CAPE) educational outcomes, ${ }^{73}$ ACPE standards, ${ }^{74}$ and additional guidelines published by the American Association of Colleges of Pharmacy (AACP) ${ }^{75}$ and other pharmacy organizations have emphasized the need to 


\section{American Journal of Pharmaceutical Education 2019; 83 (4) Article 7221.}

graduate culturally competent practitioners. The American College of Clinical Pharmacy (ACCP) has published a series of four white papers on cultural competency in health care and its implications for pharmacy. ${ }^{76-79}$ The first paper is an overview of key concepts in multicultural health care that stressed the importance of cultural competency in reducing health care disparities; specifically, the importance of congruent beliefs and expectations between the patient and the pharmacist to avoid drug misadventures. ${ }^{76}$ The second paper focuses on pharmacy systems and practice, and identifies seven components to improve culturally competent patient care: (1) analyzing self and system attitudes toward various cultures, (2) improving the knowledge of health care providers about the cultures of the people they serve, (3) engaging in effective cross-cultural communication, (4) accommodating cultural preferences in the provision of care, (5) fostering communication ties in the community, (6) adhering to regulatory requirements to enhance care for patients from various cultures, and (7) conducting quality assurance assessments. ${ }^{77}$ The third and fourth AACP papers focus on pharmacy education and the importance of inclusion and diversity among students, faculty, staff, and administrators, as well as across all aspects of academic policies and procedures. ${ }^{78,79}$ Furthermore, the papers provide guidance on teaching cultural sensitivity in pharmacy curricula to produce culturally competent pharmacists. These papers and others address cultural competency for students and practitioners within the United States. ${ }^{73-79}$ However, the key concepts can be applied to students and faculty involved in international engagements as well as in training activities in the United States.

The cultural, educational, and ethical dilemmas that arise in global outreach activities create a necessity to foster sensitivity and respect for cultural, educational, religious, historical, political, regulatory, and practice issues in health care professional students and faculty members to optimize opportunities for positive engagement. In addition, an awareness of the health care system, pharmacy education and practice, disease burden, health, and healing practices of the people in the target areas is essential. This will facilitate in developing citizens who are aware of global issues, have a sense of interconnectedness across borders, and have an understanding of their role in building bridges among diverse cultures. Thus, this special issue will serve as a resource on culturally sensitive engagement for schools and colleges of pharmacy and for others who are currently involved in or considering becoming involved in outreach opportunities in many regions of the world including within the United States. Memorandums of understand- ings should address all of the above issues from the perspective of both parties to ensure a mutually respectful accountability on both sides.

\section{METHODS}

This theme issue was developed using several methodologies. An extensive literature review was conducted using PubMed, Google Scholar, EBSCO Host, and International Pharmaceutical Abstracts databases. The search used the following keywords and combinations of keywords: culture, global, pharmacy, pharmacist, pharmacy technician, experiential education, international rotations, international global health experiences, education abroad, cultural sensitivity, culture shock, stereotype, orientalism, colonialism, health care system, and individual country names. The search was limited to publications between 2000 and 2018. Websites of specific schools and colleges of pharmacy, as well as the WHO, United Nations agencies, the World Trade Organization (WTO), World Bank, Centers for Disease Control and Prevention (CDC), and the International Pharmaceutical Federation (FIP) were also reviewed for pertinent information and referenced. The reliability of information found on the websites was assessed by the coauthors, who are content experts, based on the information's currency, depth, and accuracy. Authors from the AACP Global Pharmacy Education Special Interest Group (SIG) with expertise in global outreach in the regions of the world of interest, and authors from the AACP Health Disparities and Cultural Competency SIG were solicited to write this special issue. In addition, local authors and reviewers from the respective regions from specific countries were recruited to contribute to the manuscripts. Furthermore, US faculty members who practiced for several years in various regions also were recruited.

\section{THEME ISSUE ORGANIZATION}

The special issue consists of eight papers addressing countries in Africa, the Arab World, Asia, the Caribbean and Latin America. These regions and specific countries highlighted were deemed appropriate for this theme issue based on increased global activities in these areas by US schools and colleges of pharmacy over the last few years and a history among Americans and Westerners in general of misunderstanding the regions, countries, and people. Because of the large numbers of countries represented in Asia, two papers on this region are included. The "Arab world" designation was used rather than the "Middle East" to include representative countries among the 22 Arab countries, which share a common history, language, and culture and are part of the Arab League. The Caribbean paper included countries representative 


\section{American Journal of Pharmaceutical Education 2019; 83 (4) Article 7221.}

of the insular Caribbean. An eighth paper is included which addresses the United States and aspects unique to global engagement in different regions of the United States.

\section{Individual Papers}

In this special issue, the title of each paper is similar, emphasizing the goal of addressing cultural sensitivity in global pharmacy engagement with the specific region. The abstract of each paper will emphasize the unique aspects of the region that are not addressed in the general abstract provided in this introduction. Authors for each paper set the stage for any unique aspects of how their paper is organized and the rationale for dividing their region into subregions. Although it was impractical for this theme issue to address all the countries in the regions of interest, attempts were made to address major and representative countries within each region including those with published literature on pharmacy education and practice that documented their engagement activities with the United States. When possible, references were given to access information related to other countries not discussed in this theme issue and included the country's website and US Department of State links related to the region or a country.

The body of each paper also addresses general information such as demographics, pertinent history, religions, languages, spoken English, transportation, health care system, health and healing practices of the community, disease burden, status of pharmacy education and practice including clinical pharmacy, professional organizations, stereotypes and general guidelines for culturally sensitive practice. Where there is an indigenous culture or traditional practices, the influence these have on health and healing practices were addressed.

When addressing stereotypes, where applicable, those stereotypes related to the health care system were discussed and implications for interactions and what can be learned from the other culture are emphasized. Recommendations for culturally sensitive engagement were derived to counter identified stereotypes and any specific issues related to ethnicity, religion, country of origin, cultural norms, age and gender, family role, communication, food etiquette, concept of time, hierarchy, verbal and nonverbal communications, and other aspects that are critical for positive engagement including those related to educational differences. However, general recommendations, which are common to all regions including those for purposeful engagement for the benefit of both partners, are summarized in Table 3 . In addition to the above, a section was added on recommendations for culturally sensitive engagement when hosting students and/or faculty members from respective regions in the United States.

\section{DISCLAIMER}

The purpose of included papers is to facilitate culturally sensitive communication by promoting mutual understanding of cultures in the United States and other regions of the world. While the content is based on resources from the United States, in some cases, the current political position of the United States might differ from what the discussed country or regions identify with and publicize. However, it is not within the scope of this theme issue to discuss any political controversies. The aspects that differ between the United States and the covered countries or regions were chosen and included by primarily targeting the US audience based on US resources. The included papers do not aim to discuss or present any of the authors' political opinions or beliefs. Also, the papers should not be construed as an endorsement of any political opinion or position. The authors also do not claim to have covered all of the cultural

Table 3. Common Cultural Sensitivity Goals for All Regions of the World

Identify own stereotypes and misconception and become sensitized to them.

Establish a needs-based engagement in education, practice, service, and scholarship.

Identify historical, geographical and political factors which may influence the relationship.

Identify the role of cultural norms (eg, hospitality, accepting gifts) in hosting visitors.

Explore the role of religion and how religious practices are incorporated into daily activities, including interaction with the health care system and health care providers.

Identify the role of family and how this may affect health care decisions in patients.

Develop an understanding of the role of age, gender and authority in decision making.

Recognize unique verbal/non-verbal communication in professional interactions.

Develop an appreciation of work ethics and professional code of ethics in various cultures.

Address hierarchical or patriarchal relationships in academia and clinical practice.

Appreciate the context behind social and professional practices.

Discuss ways to address regulatory issues which impact pharmacy education and practice. 


\section{American Journal of Pharmaceutical Education 2019; 83 (4) Article 7221.}

sensitivity issues pertaining to each of the geographical regions discussed. However, with the support of local authors from the different regions, attempts were made to address, in an accurate way, some of the key issues. All the papers are meant to encourage those who are engaged in global outreach to put forth their utmost effort to educate themselves and to consult with local experts to ensure a culturally sensitive approach to their global outreach efforts.

\section{SUMMARY}

The increase in global pharmacy engagement between US institutions and institutions from different regions of the world is a welcomed development. Cultural sensitivity in such engagements is key for meeting partners where they are and where they want to go, and for establishing a sustainable relationship based on mutual benefit, respect, and reciprocity. Author Colin Woodard in his book American Nations: A History of the Eleven Rival Regional Cultures in North America contends, "In order to have any productive conversation on issues, you need to know where you come from. Once you know where you are coming from it will help move the conversation forward. ${ }^{\circ 0}$ Cultural sensitivity is a key step for moving the conversation forward in global engagement on pharmacy education and practice.

\section{ACKNOWLEDGMENT}

We would like to thank Dr. Michael D. Hogue for his valuable review of the final draft of this manuscript.

\section{REFERENCES}

1. Prescott GM, Vu BN, Alsharif NZ, Prescott WA. Global health education in doctor of pharmacy programs in the United States. Am J Pharm Educ. 2017;81(2): Article 28.

2. Miller ML, Karwa R, Schellhase EM, et al. Meeting the needs of underserved patients in Western Kenya by creating the next generation of global health pharmacists. Am J Pharm Educ. 2016; 80(2): Article 22.

3. Steeb DR, Overman RA, Sleath BL, Joyner PU. Global experiential and didactic education opportunities at US colleges and schools of pharmacy. Am J Pharm Educ. 2016;80(1):

Article 7.

4. Alsharif NZ, Dakuri A, Abrons JP, et al. Current practices in global/international advanced pharmacy practice experiences: home/ host country or site and institution considerations. Am J Pharm Educ. 2016;80(3): Article 19.

5. Dornblaser E, Ratka A, Gleason SE, et al. Current practices in global/international advanced pharmacy practice experiences (G/I APPEs): preceptor and student considerations. Am J Pharm Educ. 2016;80(3): Article 39.

6. Pointer T, Devraj R, Blankson F, Xin H. Interprofessional online global Health Course. Am J Pharm Educ. 2016;80(9): Article 155. 7. Youmans S, Ngassapa O, Chambuso M. Clinical pharmacy to meet the health needs of Tanzanians: education reform through partnership across continents (2008-2011). J Pub Health Policy 2012;33; S110-125.

8. Mantzourani E, Courtier N, Davies S, Bean G. Development of an international advanced pharmacy practice experience (APPE) and lessons learned after implementation. Curr Pharm Teach Learn. 2014;6(2):302-312.

9. A report from the Global Pharmacy Education special interest group. Connecting Global/International Pharmacy Education to the CAPE 2013 outcomes. https://www.aacp.org/sites/default/files/201710/GPE_CAPE_Paper_November_2015.pdf. Accessed March 3, 2019.

10. Al-Dhahir S, Alsharif NZ, Gleason SE, et al. Current practices in hosting non-US pharmacy students at US pharmacy schools in experiential clerkships. Am J Pharm Educ. 2017;81(9):Article 6004. 11. Pastakia S, Schellhase EM, Jakait B. Collaborative partnership for clinical pharmacy services in Kenya. Am J Hlth Syst Pharm. 2009;66:1386-1390.

12. Balley LC, DiPietro Mager NA. Global health education in doctor of pharmacy programs. Am J Pharm Educ. 2016;8(4): Article 71.

13. Bruno A, Bares I, Brock T, Anderson C. Towards a global competency framework. Am J Pharm Educ. 2010;74(3): Article 56. 14. Audus KL, Moreton JE, Normann SA, et al. Going global: the report of the 2009-2010 Research and Graduate Affairs Committee. Am J Pharm Educ. 2010;74(10):S8.

15. Map: See the 2019 Best Global Universities. https://www. usnews.com/education/best-global-universities/articles/map-wherein-the-world-are-the-best-global-universities. Accessed March 3, 2019.

16. Top 20 countries for international students. The Guardian. https://www.theguardian.com/higher-education-network/blog/2014/ jul/17/top-20-countries-international-students. Accessed March 3, 2019.

17. Wiedenmayer K, Summers RS, Mackie CA, Gous AG, Everard M, Tromp D. Developing Pharmacy Practice: A Focus on Patient Care. A 2006 Edition Handbook. World Health Organization and International Pharmaceutical Federation. https://www.fip.org/files/ fip/publications/DevelopingPharmacyPractice/

DevelopingPharmacyPracticeEN.pdf. Accessed March 3, 2019. 18. WHO. Transforming and scaling up health professionals' education and training: World Health Organization Guidelines 2013. The World Health Organization. https://apps.who.int/iris/bitstream/ handle/10665/93635/9789241506502_eng.pdf? sequence $=1$.

Accessed March 3, 2019.

19. FIP Pharmacy Education Taskforce. A Global Competency Framework for Services Provided by Pharmacy Workforce. https:// fip.org/files/fip/PharmacyEducation/GbCF\%20booklet.pdf. Published 2010. Accessed March 3, 2019.

20. Anderson C, Bates I, Brock T. Needs-based education in the context of globalization. Am J Pharm Educ. 2012;76(4): Article 56. 21. Anderson C, Futter B. PharmD or needs-based education: which comes first? Am J Pharm Educ. 2009;73(5): Article 92.

22. Anderson C, Bates I, Beck D. The WHO UNESCO FIP Pharmacy Education Taskforce: enabling concerted and collective global action. Am J Pharm Educ. 2008;72(6): Article 127. 23. FIP. 2012 FIP Global Pharmacy: Workforce Report.

International Pharmaceutical Federation (FIP). http://www.fip.org/ static/fipeducation/2012/FIP-Workforce-Report-2012/?

page $=$ hr2012. Accessed March 3, 2019.

24. Framing the Health Workforce Agenda for the Sustainable Development Goals: Biennium Report 2016-2017 WHO Health 


\section{American Journal of Pharmaceutical Education 2019; 83 (4) Article 7221.}

Workforce. Geneva: World Health Organization. http://apps.who.int/ iris/bitstream/handle/10665/272600/WHO-HIS-HWF-

bienniumreport-2017.1-eng.pdf?ua=1. Accessed March 3, 2019. 25. Accreditation Council for Pharmacy Education. Directory of Programs with Certification Status. https://www.acpe-accredit.org/ pdf/ISP/DirectoryofCertifiedPrograms.pdf. Accessed March 3, 2019. 26. American Society of Health-System Pharmacists Online Residency Directory. https://accred.ashp.org/aps/pages/directory/ residencyprogramsearch.aspx. Accessed March 3, 2019.

27. Accreditation Council of Pharmacy Education. https://www. acpe-accredit.org/. Accessed March 3, 2019.

28. Board of Pharmacy Specialties. International Applicant Helpful Tips. https://www.bpsweb.org/wp-content/uploads/InternationalApplicant_Helpful_Tips.pdf. Accessed March 3, 2019.

29. Board of Pharmacy Specialties. BPS 2017 Annual Report. https://board-of-pharmacy-specialties.dcatalog.com/v/2017-AnnualReport/\#page = 10. Accessed March 3, 2019.

30. Said E. Orientalism. New York: Vintage Books; 1979.

31. Matsumoto D. Culture, context and behavior. J Personality. 2007 December;75(6):1285-1319.

32. Campinha-Bacote J. The process of cultural competence in the delivery of healthcare services: a model of care. J Transcult Nurs. 2002;13:181-184.

33. Foronda C. Cultural humility: a concept analysis. J Transcult Nurs. 2016;27(3):210-217.

34. Chang MS, Dong X. Integrating cultural humility into health care professional education and training. Adv Health Sci Educ.

2012;17:269-278.

35. Betsch C, Bohm R, Airhihenbuwa CO, et al. Improving medical decision making and health promotion through culture-sensitive health communication: An agenda for science and practice. Med Decis Making. 2016; 36(7):811-833.

36. Vidaeff AC, Kerrigan AJ, Monga M. Cross-cultural barriers to health care. Southern Med J. 2015;108(1):1-4.

37. Dawe R, Pike A, Kidd M, Janakiram P, Nicolle E, Allison J.

Enhanced skills in global health and health equity: guidelines for curriculum development. CMEJ. 2017;8(2):e48-e60.

38. Hutchins FT, DiPrete L, Poulsen KP. An anthropological approach to teaching health sciences students' cultural competency in a field school program. Acad Med. 2014;89(2):251-256.

39. Karnick PM. Sorting it out: cultural competency in healthcare literacy in the world today. Nurs Sci Quarterly. 2016;29(2):120-121. 40. Lin C, Lee C, Huang M. Cultural competence of healthcare providers: a systematic review of assessment instruments. J Nurs Res, 2016;25(3):174-186.

41. Safipor J, Wenneberg S, Hazdziabdie E. Experience of education in the international classroom: a systemic literature review. $J$ Int Students. 2017;7(3):806-824.

42. Young JT. Confucianism and accents: understanding the plight of the Asian international student in the U.S. J Int Students.

2017;7(3):433-448.

43. DuBose C. But I don't understand you: one faculty's observations of the challenges facing international healthcare students. J Int Students. 2017;7(1):154-159.

44. Perry CJ. Comparing international and American students' challenges: a literature review. J Int Students 2016;6(3):712-721. 45. Gatwiri G. The influence of language difficulties on the wellbeing of international students: an interpretive phenomenological analysis. Inquiries $J$. 2015;7(05):1-2.

46. Green B. "What difference does a difference make?" In:

Diversity in Human Interaction: The Tapestry of America. Ed. John
D. Robinson \& Larry C. James. Oxford: Oxford UP, 2003. 3-20. Print.

47. Andrade MS. International students in English-speaking universities adjustment factors. J Res Inter Educ. 2006;5(2):131-154. 48. Heitman E, Litewka S. International perspectives on plagiarism and considerations for teaching international trainees. Urol Oncol. 2011;29(1):104-108.

49. Simpson D. Academic dishonesty: an international student perspective. Acad Perspectives Higher Educ. 2016;2(1): Article 5. 50. Cardwell M. Stereotypes. http://www.simplypsychology.org/ katz-braly.html. Accessed March 3, 2019.

51. Banaji MR, Greenwald AG. Implicit stereotyping and prejudice. In: The Psychology of Prejudice. The Ontario Symposium. M.P. Zanna \& J.M. Olson. Eds Hillsdale, NJ: Erlbaum. 1994;7:55-76. 52. Berry JW. Immigration, acculturation and adaptation. Appl Psych. 1997;46(1):5-34.

53. Oberg K. Culture shock: adjustment to new cultural environment. Pract Anthropol. 1960;7:177-182.

54. Lysgaard S. Adjustment in a foreign society: Norwegian Fulbright grantees visiting the United States. Int Soc Sci Bull. 1955;7:45-51.

55. Demes KA, Geeraert N. The highs and lows of cultural transition: a longitudinal analysis of sojourner stress and adaptation across 50 countries. J Pers Soc Psychol. 2015; 109(2):316-337. 56. Hamboyan H, Bryan AK. International students. Culture shock can affect the health of students from abroad. Can Fam Phys. 1995;41:1713.

57. Ching Y, Renes SL, McMurrow S, Simpson J, Strange T. Challenges facing Chinese international students studying in the United States. Educ Res Rev. 2017;12(8):473-483.

58. Tung ML. The roots of the challenge: undergraduate Chinese students adjusting to American college life. Int J Higher Educ. 2016;5(3):121-130.

59. Sharif MKI, Osterling PI. China's re-emergence: sociolinquistic challenge faced by Chinese international students enrolled in U.S. universities. Int Res Rev. 2011;1(1):63-72.

60. Joy S, Kolb D. Are there cultural differences in learning style? Int $J$ Intercult Relations. 2009;33: 69-85.

61. McKay JI, O’Neill D, Petrakieva LI. CAKES (Cultural

awareness and knowledge exchange scheme): a holistic and inclusive approach to supporting international students. J Further Higher Edu. 2018; 42(2):276-288.

62. Safipour J, Wenneberg S, Emina H. Experience of education in the international classroom: a systemic literature review. J Int Students. 2017;7(3):806-824.

63. Ventres WB, Wilson CL. Beyond ethical and curricular guidelines in global health: attitudinal development on international service-learning trips. BMC Med Educ. 2015;15:68.

64. Crump JA, Sugarman J. Ethics and best practice guidelines for training experiences in global health. Am J Trop Med Hyg.

2010;83(6):1178-1182.

65. Childress J, Beauchamp T. Principles of Biomedical Ethics. New York: Oxford University Press, 2001.

66. Bertkau A, Halpern J, Yadia S. The privileges and demands of professional self-regulation. AMA J Ethics. April 2005;7(4).

67. Prainsack B, Buyx. Solidarity: Reflections on an emerging concept in ethics. Nuffield Council on Medical Bioethics. http:// nuffieldbioethics.org/wp-content/uploads/2014/07/Solidarity_ report_FINAL.pdf. Published 2011. Accessed March 3, 2019. 68. Dawson A, Verweij M. Solidarity: a moral concept in need of clarification. Public Hlth Ethics. 2012;5(1):1-5. 


\section{American Journal of Pharmaceutical Education 2019; 83 (4) Article 7221.}

69. Byrne S, Collins SD, Ojemeni MT. Sustainable global health outreach in Haiti: Service learning for primary care nurse practitioner students. J Nur Practitioner. 2014; 10(8) e33-e40.

70. Feehally J, Brusselmans A, Finkelstein FO, et al. Improving global health: measuring the success of capacity building outreach programs: a view from the international society of Nephrology.

Kidney Int Supplements. 2016;6(2):42-51.

71. Alsharif NZ. Purposeful global engagement in pharmacy education. Am J Pharm Educ. 2017;81(10):Article 6882.

72. American Pharmacists Association. Code of Ethics: Code of ethics for pharmacists. https://www.pharmacist.com/code-ethics. Accessed March 3, 2019.

73. Medina MS, et al. Center for the Advancement of Pharmacy Education Educational Outcomes 2013. Am J Pharm Educ. 2013;77(8):162.

74. Accreditation Council for Pharmacy Education. Accreditation standards and key elements for the professional program in pharmacy leading to the Doctor of Pharmacy Degree. ("Standards 2016"). https://www.acpe-accredit.org/pdf/Standards2016FINAL.pdf.

Published February 2015. Accessed March 3, 2019.

75. Libraries/Education resources section of the American Association of Colleges of Pharmacy. Cultural Competency: Selected resources for instruction. https://www.aacp.org/sites/default/files/
2017-11/FinalBibliography.pdf. Published July 2006. Accessed March 3, 2019.

76. O’Connell MB, Korner EJ, Rickles NM, Sias JJ. Cultural competence in health care and its implications for pharmacy. Part 1: overview of key concepts in multicultural health care.

Pharmacotherapy. 2007;27:1062-79.

77. O'Connell MB, Rickles NM, Sias JJ, Korner EJ. Cultural competency in health care and its implications for pharmacy. Part 2: emphasis on pharmacy systems and practice. Pharmacotherapy. 2009;29:14e-34e.

78. O'Connell MB, Rodriguez de Bittner M, Poirier T, et al. Cultural competency in health care and its implications for pharmacy part 3A: emphasis on pharmacy education, curriculums, and future directions. Pharmacotherapy. 2013;33:e347-67.

79. O'Connell MB, Jackson AN, Karaoui LR, et al. Cultural competency in health care and its implications for pharmacy Part 3B: emphasis on pharmacy education policy, procedures, and climate. Pharmacotherapy. 2013;33: e368-381.

80. Woodard C. American Nations: A History of the Eleven Rival Regional Cultures of North America. New York, NY: Penguin Group (USA); 2011. 